colour, the descent of which doubtless had occasioned the severe symptoms and fetal termination of the case.

Rexares. The propar mode of combating with success cases like this must at once be apparent; as, although the hemial protrusion may be very difficult of detection, from the superincumbent tumour, yet, if there are unequirocal symptoms of intestinal obstruction, I think it will be conceded that we are justified in making an exploratory incision, by which, as occurred in Mr. Brown's interesting case, above referred to, we may sometimes succeed in rescuing a patient from much suffering, and indeed impending death.*

Manchester, October 1854.

\section{FATAL CASE IN WHICH AN AGED LADY WAS NINE WEEKS WITHOUT AN EVACUATION OF FACES.}

\section{By THOMaS G. WALES, Esq.}

TeE following case will, I think, be interesting to the readers of the Assocration Jodrsul, when it can appear without displacing more valuable matter. It might have been successfully treated in other hands; but I am one of many who would not suppress a case of failure in our art, from a conviction that the acknowledgment of our inability in difficulties may be suggestive to others, who may have to manage cases of like character, of what they ought to do, and of what they ought to leave undone. In the case which I am about to narrate, heroic practice with purgative remedies, beyond the extent to which they were adopted, would, I am persuaded, have deprived my aged patient of some weeks of comparative enjoyment of life, and rendered me liable to a very common imputation, Nimia diligentia medicince. I lament that I had not a post mortem examination.

Case. Miss S., a spinster lady, in her serenty-first year, of small stature and rosy complexion, having had good health and active habits, applied to me July 8th this year for relief. She explained that the state of her bowels was such as to make her uncomfortably apprehensive of going abroad, and frequently to occasion her leaving the table at meals. Her general health was good; and for some days, whilst she continued her social habits with the family, her symptoms were treated with simple carminative and astringent remedies. To the end of this month, nothing more than had been long experienced induced her to call my attention.

Aug. 3rd. A smart attack of colic pains caused my being again called to her. Miss $S$. being now under nursing, I had a better opportunity of learning the nature of what she had called a diarrhoea. The abdomen was now tympanitic, and the desire to defecate incessant, without the power to evacuate anything.

The following three days and nights were diligently employed in all justifiable means to move the bowels, including full doses of opium and calomel, and subsequently croton oil, oily and turpentine injections, without obtaining an advantage; indeed, the stomach became irritable, and rejected all that was swallowed.

Aug. 6th. I proposed a consultation with Dr. Cotton of Lynn, whose penetration and good judgment, I think, must be allowed, when the results are known. On this day, the tympanitic symptom persisted, and sound was dull only over a small space in the right iliac region. The future treatment, as will be seen, consisted of moderate doses of morphia and chloroform. In the evening of this day, a pound and a half of quicksilver was swallowed.

- John Horeteld, the subject of this paper, although only a weaver by trade, wes distinguished for his botanical knowledge generally, but espe. cilly of English plants, and formed one of a band of most zealous fallow. Ibourus in that department of nataral soience, who have long aseociated thomedres together in this noighbourbood, and have regular meetinger for an parpose of motend information on botanieal subjects.
I will now transcribe the notes I made to Dr. Cotton of the six consecutive days :-

The pulse had been and was firm, about 80 , except after vomiting. There were no rigors or heat during the attack. I was now bent on agreeing with my colleague, that as little interruption to the vis medicatrix natura as was consistent with circumstances should be offered.

Aug. 7th. She had a good night, and passed a little fiatus downwards. There had been no return of pain or sickness, and she was without complaint. She took gruel with a little brandy at intervals, and extended the period between the doses of medicine. She remained comfortable till 9 P.x., but had no alvine evacuation.

Aug. 8th. She was without complaint, and passed flatus occasionally. Tympanitis was much less. She continued to take nourishment in a fluid state. She slept at intervals. There was no sickness. She sat up two hours, and walked a little about her room. At nine o'clock in the evening, she was comfortable. The abdominal distension had quite subsided. There had been no evacuation. I could feel the quicksilver in the colon, and make it imitate the quickening of a fotus.

Aug. 9th. The patient had a good night, and was much the same in all respects. The medicine had been given only twice in twelve hours. The abdomen was flat, and bore rough handling without pain. I passed my finger, to ascertain the state of the rectum, as far as I could reach; I detected a narrowing of the gut, without induration or pain being complained of by the patient. I conjectured there must be invagination of the bowel. I gave a large simple enema, which was retained half an hour; and, when returned, brought away a very hard olive coloured lump of fæces, of the size of a French walnut. The patient took two ounces of castol oil, on brandy and water, which was retained. At nine in the evening, she was comfortable, and begged to be let alone.

Aug. 10th. The oil had been retained. The patient had had a good night, and had no complaint. She continued to take nourishment enough. The stomach was quiet. The enema was repeated morning and night. There was no movement of bowels.

Aug. 11th. The patient seemed quite well; she sat up and walked about. The oil and enema were repeated: the former was returned after an hour; and the latter came away colourless and without scybala.

Aug. 12th. She was as well as yesterday, but cared little about nourishment. She preferred to be let alone. She slept enough; and thought it so odd that, with the exception of weakness, she felt well.

Aug. 13th. Having no rectum bougie by me, I shaped a Palmer's lamp-candle, and tried to pass it into the narrowing of the bowel; this was attended with pain. Unwilling to do this without achieving some good, I cut off the lower part, and left the other, about six or seven inches, kept steady by the sphincter. I hoped that, when this might be expelled by a consent of parts, something above might come down into the pouch, which at present contained nothing to soil the finger.

Aug. 14th. The candle was ejected five hours after its introduction, but was neither accompanied nor followed by discharge. She had a fair night; but was once sick, after taking some tea which was without brandy. She longed for some champagne; and begged to be let alone.

From this date to her death, on the 6th of October, life was prolonged without pain. She was supported by bitter ale and gruel. Nine weeks, as near as I can ascertain, had elapsed, without an evacuation of faces. She expired under syncope, after removal from her bed to the night-chair, for the purpose of emptying the bladder.

Duwnham Market, Norfolk, Oct. 2i, 1854. 